\title{
Cytotoxic or cytoprotective chaperones: An unfolded biology in oral lesions
}

\author{
Bina Kashyap ${ }^{1 *}$, Sridhar Reddy $\mathrm{P}^{2}$ and Jagadish Prasad Rajguru ${ }^{3}$ \\ ${ }^{1}$ Department of Oral Pathology, Buraydah Private Dental College, Buraydah, Saudi Arabia \\ ${ }^{2}$ Department of Oral \& Maxillofacial Surgery, Buraydah Private Dental College, Buraydah, Saudi Arabia \\ ${ }^{3}$ Department of Oral Pathology, Hitech Dental College \& Hospital, Pandora, Bhubaneshwar, India
}

\begin{abstract}
Heat shock proteins (Hsp) or the molecular chaperones are observed in most cells of humans, microbes, and in extracellular and intracellular fluids. Hsps plays an essential role under most stress conditions at the cellular and subcellular levels. It presents cytoprotective properties by the modulation of cytokine release and immunity and is involved in various physiological and pathological events. A tight regulation of molecular chaperones monitors the folding/misfolding, internal localization, and proteolytic turnover of proteins. Despite their advantageous effects, Hsps also has disadvantageous role in intensifying the inflammation. They are potential mediators of oncogenesis as they are the key regulators of cellular growth and differentiation. The authors reviewed, an overview of the role of chaperones, with respect to the lesions affecting oral and para-oral structures.
\end{abstract}

\section{Introduction}

Cells in the human body are exposed to various physical, chemical, radiological, environmental and iatrogenic injuries, some of which can be withstand and/or some of it produces harmful effects. These special challenges are faced by the cell \& it's organelles in the form of high protein load, molecular crowding, dynamic oligomerization etc. The proteins that are synthesised to overcome such environmental stresses have been variously called heat-shock proteins (Hsps), stress proteins or molecular chaperones, a family of abundant, evolutionarily conserved proteins that directly bind to protein substrates [1].

Molecular chaperones are defined as "any protein that interacts, stabilizes, or helps a non-native protein to acquire its native conformation, but is not present in the final functional structure". The term molecular chaperone, coined by Laskey and colleagues in 1978 [2], occurs in all organisms as they are crucial for the cell survival. In the past 20 years, it has been established that, within the cytoplasm of the cell, the molecular chaperones interact with other proteins to fold, refold or maintain the folding of the interacting proteins. Molecular chaperones perform some essential cellular functions, such as metabolism, growth, differentiation, cell to cell signaling and programmed cell death, through protein assembly and transport. Hence, the activities of housekeeping tasks and stress protection are based on their ability to interact, stabilize and protect bound polypeptides by preventing irregular interactions leading to denaturation and aggregation [2-7].

The chaperones are classified according to their molecular weight Hsp40, Hsp60, Hsp70, Hsp90, Hsp100 and the "small" Hsps, less than $35 \mathrm{kDa}$. (Table 1) The first molecular chaperone to be identified was a $60-\mathrm{kDa}$ protein, which has been given the generic term chaperonin 60 (cpn60). Till now, 15 different groups of proteins are classified as molecular chaperones. In the cell, there is complex interactions among several chaperone members to play distinct roles, as they exhibit little structural or sequence homology. For example, the function of many Hsp40 occurs via their actions on Hsp70 $[8,9]$.

\section{Chaperone role in Protein aggregation}

Chaperones that to become functionally active, newly synthesized protein chains must fold to unique three-dimensional structures and the method this happens always remains a basic problem in biology. In vitro refolding experiments showed that the native fold of a protein is encoded in its amino acid sequence. Spontaneous refolding is generally efficient for small, single-domain proteins. In contrast, larger proteins are composed of multiple domains often refold inefficiently, owing to the formation of partially folded intermediates, including misfolded states, that tend to aggregate. The nonnative states, being compact in shape, often exposes hydrophobic amino acid residues and segments of unstructured polypeptide to the solvent. The hydrophobic forces and inter chain hydrogen bonding allows the protein to self-associate into disordered complexes. This aggregation process irreversibly removes proteins from their productive folding pathways, which must be prevented in vivo by the molecular chaperones $[10,11]$.

The cellular chaperone apparatus counteracts the aggregation of nonnative proteins, both during de novo folding and under conditions of stress, such as high temperature, when some native proteins unfold. Chaperones that participate broadly in de novo protein folding, such as the Hsp70s and the chaperonins, promote the folding process through cycles of substrate binding and release regulated by their adenosine triphosphatase (ATPase) activity and by cofactor proteins. Chaperone binding may not only block intermolecular aggregation directly by shielding the interactive surfaces of non-native polypeptides, including

Correspondence to: Bina Kashyap, Department of Oral Pathology, Buraydah Private Dental College, Buraydah, Saudi Arabia, Tel: +966 504663028; E-mail: binakashyap@yahoo.co.in

Key words: chaperones, cellular, cytoprotective, heat shock proteins, immunity, oncogenesis

Received: May 04, 2017; Accepted: May 25, 2017; Published: May 29, 2017 
Table 1. Chaperones classified with different molecular weight.

\begin{tabular}{|c|c|c|c|c|}
\hline S.No & Molecular Cheperones & Related proteins & Co-cheperons & Function \\
\hline 1 & Hsp 10 & $\begin{array}{l}\text { cpn10, hsp10, co-chaperonin, early } \\
\text { pregnancy factor, GroES }\end{array}$ & Hsp 60 & It promotes folding of substrates that are bound to chaperonin 60 \\
\hline 2 & Small Hsps & - & - & $\begin{array}{l}\text { Diverse class of proteins. } \\
\text { Chaperone function is independent of adenosine triphosphate (ATP) } \\
\text { It binds to non-native proteins }\end{array}$ \\
\hline 3 & Hsp 40 & DnaJ related & Hsp 70 & $\begin{array}{l}\text { Co-chaperones that regulate the activity of hsp } 70 \text { proteins. } \\
\text { It binds to non-native proteins. }\end{array}$ \\
\hline 4 & Hsp 60 & cpn60, hsp60, hsp65, GroEL & Hsp 10 & ATP-dependent pathway causing assemble/disassembly of proteins. \\
\hline 5 & Hsp 70 & - & Hsp 40 & $\begin{array}{l}\text { Prevent the aggregation of unfolded polypeptides } \\
\text { Refolding multimeric protein complexes Protein trafficking Regulate the heat-shock } \\
\text { response }\end{array}$ \\
\hline 6 & Hsp 90 & - & Hsp 70 & Regulate signal transduction pathways, Might have 'general' chaperone activity \\
\hline 7 & Hsp 100 & - & Hsp 70,90 & Disassemble protein oligomers and aggregates \\
\hline 8 & Hsp 110 & - & - & $\begin{array}{l}\text { High degree of homology with the hsp } 70 \text { family. } \\
\text { Functions are less known. }\end{array}$ \\
\hline
\end{tabular}

unassembled protein subunits, but may also prevent or reverse intramolecular misfolding. The small proteins are thought to fold rapidly and without assistance, upon completion of synthesis whereas longer chains intermingle with members of another class of chainbinding chaperones. The chaperones assist in co- or posttranslational folding, or facilitate chain transfer to downstream chaperones so as to stabilizing elongating chains. Chaperones participate mainly through two different mechanisms. One by holding newly synthesized chains in a state competent for folding upon release into the medium and second by providing physically defined compartments inside which a complete protein or a protein domain can fold while being sequestered from the cytosol. These two classes of chaperone collaborate in a topologically and timely ordered manner [12-18].

\section{Heat shock proteins}

Hsp40: It represents a large protein family that functions to specify the cellular action of $\mathrm{Hsp} 70$ chaperone proteins. Hsp40 family members have different domain structures and can be divided into 3 different subtypes. Type I Hsp40s are descendants of Escherichia coli DnaJ, Type II Hsps40 have a domain structure similar to that of DnaJ and Type III have divergent structures. Type I and Type II Hsp40s function as ATP-independent chaperones that bind nonnative polypeptides and protect cells from stress by preventing protein aggregation. Type III Hsp40s do not appear to be general chaperones and have evolved to contain PPDs (polypeptide-binding domains) that recognize specific substrates [19-21].

The major function of Hsp40 proteins is to regulate adenosine triphosphate (ATP)-dependent polypeptide binding to Hsp70 protein. It regulates complex formation between $\mathrm{Hsp} 70$ and polypeptides by 3 mechanisms. First, Hsp40 proteins have evolved to contain unique classes of polypeptide-binding domains (PPDs) that bind and deliver specific clients to Hsp70. Second, Hsp40 proteins stabilize Hsp70 polypeptide complexes by driving the conversion of $\mathrm{Hsp} 70$ from its ATP. Third, specialized members of the Hsp40 family are localized to different sites within the same cellular compartment [19,22-28].

The domain in Hsp40 proteins that is responsible for regulation of Hsp70 ATPase activity is the J-domain, and it is present in all Hsp40 family members. The J-domain was first identified in $E$ coli DnaJ and contains a conserved HPD tripeptide that represents the signature motif of the Hsp40 protein family. Landry 2003, in their studies on the molecular dynamics of J-domain-Hsp70 interactions demonstrated that the J-domain exists in a dynamic group of conformations. The ability of the J-domain to stimulate Hsp70 ATPase activity is enhanced by the presence of peptides bound in the polypeptide-binding site of Hsp70. Because ATP hydrolysis leads to a conformational change in Hsp70, a mechanism for inter domain communication between the ATPase and PPD of Hsp70 appears to exist [29-33].

Hsp60: It is the first molecular chaperones recognized as a 60$\mathrm{kDa}$ protein and was given the basic term chaperonin 60 . Members of the chaperonin 60 family have a characteristic double-ring structure comprising 14 subunits which forms a large central cavity in which the unfolded protein substrate binds via hydrophobic interactions. Hsp 60 belongs to proteins of the GroE subclass, which is well-characterised, sequence-related subgroup of molecular chaperones. Till date, GroEL, the E. coli chaperonin 60 protein, is the most extensively studied molecular chaperone. Ewalt and colleagues in 1997 experimented that under normal growth conditions, GroEL folds $10-15 \%$ of all cytoplasmic proteins which increases to $30 \%$ under heat stress conditions [34-37].

The crystal structure of GroEL shows three domains 1) apical domain: here both the substrate and GroES bind 2) equatorial domain: it contains a binding site for adenosine triphosphate (ATP) and the contacts for ring binding 3 ) intermediate domain - it connects apical and equitorial domains. The intermediate domain acts as a hinge, effecting conformational changes when ATP is bound, and causing the substrate-binding surface to alternate between hydrophobic and hydrophilic states. In the hydrophobic state, a protein substrate binds to GroEL, therefore checking the misfolding. When ATP binds to GroEL, the intermediate domain opens up, changing the substratebinding surface so that it becomes hydrophilic and release the protein substrate. The Hsp 60 oligomers associate with Hsp 10 oligomers to affect their functions. When ATP is bound to Hsp 60, the Hsp 10 forms a lid on top of the chaperonin 60 barrel and causes the central cavity to enlarge, thus aiding protein folding [35,38-41].

Hsp60, after continued research showed that it presents another distinct set of functions. The earliest indication presented, other than protein folding, was that chaperonin 60 could produce pores in membranes. It can stimulate the release of proinflammatory cytokines from human monocytic cells (Ref. 44), stimulate leukocytes, fibroblasts, epithelial cells and synthesis of adhesion molecules. A very potent activity that has been certified to chaperonin 60 is bone resorption. Later, other molecular chaperones like Hsp70 and Hsp90 have also been found to stimulate bone resorption in in-vitro models [1,42-44].

Hsp70: The Hsp70 family of molecular chaperones is one of the most conserved protein families and it is found in all eukaryotic and 
prokaryotic organisms apart from some hyperthermophilic archaea. The characteristic, non-ribosome-binding members of the Hsp70 family happen to occur in the cytosol as well as within eukaryotic organelles, such as mitochondria and endoplasmic reticulum. The cytosol appears to contain Hsp70 homologs (Hsc70) and stress-inducible forms (Hsp70) of Hsp 70. Hsp 70 family members co-localizes in the same subcellular compartment with multiple members of the Hsp40 family (co-chaperones) that have specialized individual functions. Single Hsp70 (DnaK) interaction with multiple Hsp40s (DnaJ, a 75-residue protein) produces $\mathrm{Hsp} 70-\mathrm{Hsp} 40$ pairs that facilitate specific processes at distinct locations within the cell and assist in capturing substrate proteins [12,20,45-51].

Hsp70s have two major functional domains, an ATPase domain (or nucleotide binding domain, NBD) of around $40 \mathrm{kDa}$ at the $\mathrm{N}$-terminal, and a C-terminal peptide binding domain (PBD), of approximately 25 $\mathrm{kDa}$. The Hsp70-Hsp40 pairing starts, when DnaJ binds a segment of misfolded protein and transports it to DnaK at peptide-binding groove. ATP hydrolysis at $\mathrm{N}$-terminal domain of Hsp70 locks the protein in its groove. Then DnaJ dissociates and the substrate is released by binding GrpE chaperone to Hsp70. DnaK system with its co-chaperones barely change the configuration of misfolded protein instead it provides a protected milieu for complete folding of substrate (Figure 1).

The human Hsp70 family consists of 13 different proteins observed within the cytosol and nuclear compartment which became apparent upon completion of the human genome project. Albanese, et al. suggested two distinct groups of Hsp70s: 1) Stress chaperones that are induced in periods of stress and 2) "Housekeeping" or "CLIPS" (chaperones linked to protein synthesis) are repressed by stress, and transcriptionally co-regulated with the translational apparatus [52-55].

Gabai and Mosser, et al. showed incredible Hsp70 cytoprotective properties. Overexpression of Hsp70 alone can prevent stress-induced apoptotic death. Hsp70 has been demonstrated to affect processes regulating apoptotic signaling, effector molecule activation, and events downstream of caspase activation. On the other hand, the Hsp70 can also be traced in upstreaming apoptosome formation. It is achieved due to overexpression of $\mathrm{Hsp} 70$ which prevents the release of cytochrome $\mathrm{c}$ and apoptotic induced factor from mitochondria. $\mathrm{Li}$, et al. contradicted by suggesting that overexpression of Hsp70 have no effect on stress-

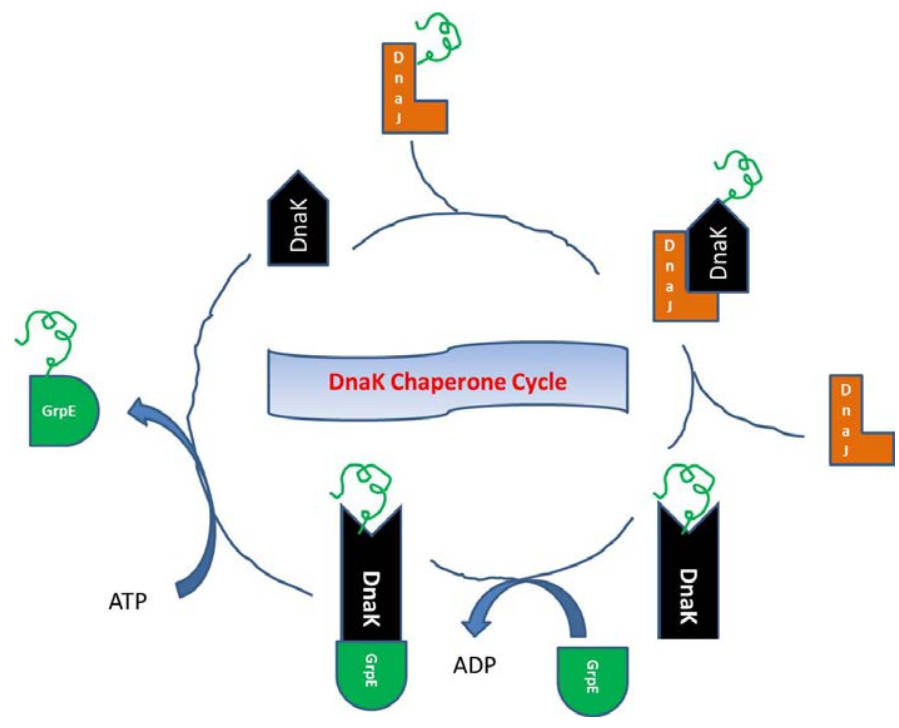

Figure 1. Photograph showing Hsp70-Hsp40 pairing with Dnak System. induced cytochrome c release in the experimented cells, although it did prevent caspase-3 activation [56-60].

Hsp90: Hsp90 is abundant in eukaryotic cells and its expression increases when cells are exposed to a variety of stresses. It is a key regulator of folding of newly synthesized or misfolded proteins, preventing their aggregation and regulates various other cellular proteins called as 'clients'. Hsp90 contains three domains: N-terminal ATP-binding domain, middle domain and carboxy-terminal domain. All examined forms of Hsp90 bind and hydrolyze ATP. After hydrolysis Hsp90 returns to its vulnerable conformation.

Hsp90 and co-chaperone proteins interact with client proteins in systematic pathway involving ATP-dependent interactions of the client protein. Hsp90 is called 'molecular chaperone machine', because no evidence supports that Hsp90 exists alone as one large complex. As an alternative, Hsp90 and co-chaperone proteins interact with client proteins in an ordered pathway. Wegele $\mathrm{H}$, et al. and Zhao $\mathrm{R}$, et al. in their study showed that the newly synthesized or misfolded client interacts first with Hsp40 and Hsp70 later transfer this client protein from Hsp70 to Hsp90. Co-chaperone binding varies due to varied conformational changes of Hsp 90 [61,62].

To date known forms of Hsp90 perform role in supporting client folding and stimulating to maintain the general biosynthesis and homeostatic cell needs towards varied array of stress conditions. Pandey, et al. in 2000 observed Hsp90 in the stress-induced apoptotic pathway where it binds to Apaf-1(Apoptotic activating factor) and prevents the cytochrome c mediated oligomerization of Apaf-1. Also, suggested that under stressed condition, Hsp90 competes with cytochrome $\mathrm{c}$ to bind with Apaf-1, thereby the amount of Hsp90 associated with Apaf-1 decreases and the cytoplasmic levels of cytochrome $c$ increase. Thereby, confirming that Hsp90 might inhibit premature activation of Apaf-1 [63].

Hsp100: Proteins of the Hsp100 family, also called as Clp proteins. Hsp100 are implicated in the re-solubilization of protein aggregates and in the unfolding of proteins. Hsp100 also assist the degradation of irreversible damaged polypeptides by specific proteolytic machineries. It cooperates closely, both in structure \& in function, with specific proteases mediating protein turnover. It is thought that Hsp100 in cooperation with Hsp70 supply an unfolding activity required for the efficient and complete proteolytic degradation of misfolded substrate proteins [64].

Hsp100, high molecular weight heat shock protein, exists in homodimeric form under physiological conditions. It has similar physiochemical properties with Hsp90. Koyasu S, et al. in 1986, suggested that Hsp 100 are actin-binding proteins that can cross-link actin filaments. This cross linking is accelerated along with Hsp 90. Both Hsp90 and Hsp100 increase the low-shear viscosity of filamentous actin solutions in a dose-dependent manner. Also some molecular properties and the effects of Hsp90 \& Hsp100 resemble those of $\alpha$-actinin. These Hsps were distinguished from $\alpha$-actinin by various means such as visualization of molecular shapes by electron microscopy with the aid of the low-angle rotary shadowing technique [65].

The first member of the Hsp100 family identified in mitochondria is Hsp78. Under normal growth conditions, mutants of Hsp78 do not show major defects. Under severe temperature stress, Hsp78 becomes more important for the maintenance of mitochondrial function. Especially reactivation of the mitochondrial protein synthesis machinery is dependent on the presence of Hsp78 [66]. 


\section{Small heat shock proteins}

Small heat shock proteins (sHsps) have multiple cellular functions including modulation of cytoskeletal dynamics, balance of membranes and apoptosis. Small heat shock proteins do not have an ATP binding site like other Hsps, however, most of the studies showed that ATP somehow affects the structure of sHsps and their interaction with protein substrate. These may partially interact with denatured proteins, prevent their aggregation and under required situation transfer partially denatured substrates to other chaperones possessing ATPase activity $[67,68]$.

The sHsp family is characterized by the presence of a " $\alpha$-crystallin" domain, derived from the eponymous mammalian sHsp. This central domain is flanked by $\mathrm{N}$ and $\mathrm{C}$-terminal region. The $\mathrm{C}$-terminal region is generally considered to have two segments, termed as "tail" and "extension". The extension appears to be present primarily in higher eukaryotes. The N-terminal region is however essentially omnipresent and is longer. It shows almost no sequence conservation, and is responsible for the majority of the sequence variation between sHsps in the same organism. Also, sites for post-translational modification appear largely in this portion of the protein. Hence, it is possible that the variability at the $\mathrm{N}$-terminus may have a part to play in cell's unit of sHsps which can recognize a wide range of target proteins [69-72].

Five major classes of small heat shock proteins are synthesized by vertebrates. These are $\alpha \mathrm{A}$ and $\alpha \mathrm{B}$ crystallin, small heat shock proteins with molecular weight $25-27 \mathrm{kD}$ (Hsp25/27), small heat shock proteins with molecular weight $20 \mathrm{kD}$ (Hsp20), small heat shock proteins with molecular weight $17 \mathrm{kD}$ (HspB3), and HspB2 (activator of myotonic dystrophy protein kinase). Hsp27, a small Hsp, in contrast to the other major chaperones, can efficiently associate with unfolded proteins and preserve them in a folding competent state. The chaperone activity of Hsp27 is regulated by heat-induced changes in phosphorylation and oligomerization. It is a potent cell survival factor that contributes to thermotolerance. Guay, et al. in 1997 revealed that Hsp27 binds to F-actin and can prevent disruption of the cytoskeleton resulting from either heat stress or cytochalasin D-induced disruption of actin filaments. In a study by Garrido, et al. in 1999, Hsp 27 inhibited components of stress and death-receptor induced apoptotic pathways. The cells expressing higher levels of Hsp27 showed caspase activation not cytochrome $\mathrm{c}$ release in the apoptotic pathway. Kamradt, et al. in 2001 suggested that the small Hsp family have a - crystallin proteins that have chaperone activity and can protect cells from apoptosis [73-76].

Benndorf, et al. stated that unphosphorylated monomeric forms of Hsp25 effectively block actin polymerization, whereas phosphorylated monomers and unphosphorylated oligomers are ineffective in preventing actin polymerization. This lead to accept the fact that Hsp25 is an inhibitor of actin polymerization. Under normal conditions Hsp25 is diffusely distributed in the cytoplasm. Certain hormones such as cholecystokinin, endothelin, angiotensin II, growth factors, and ceramides causes redistribution and migration of Hsp25 to membranes where it is co-localized with actin filaments and stress fibers. If the heat shock activity occurs under depletion of ATP, the Hsp25 do not migrate instead forms large aggregates (granules) in the nucleus or in the cytosol. Heat shock induces aggregation of intermediate filaments and Hsp25/27 as well as $\alpha \mathrm{B}$ crystallin interacts with these aggregates [77-81].

\section{Role of heat shock proteins}

Heat shock proteins are now known to occur in all organisms and are essential for the cell survival. As with recent advances, more information about Hsp functions became available. The heat-shock proteins serve as cellular housekeeping, safeguards to protect the interaction with proteins that are either unfolded or have not acquired their native conformation. As chaperones can act at multiple points to ensure stress-induced damage, it has been difficult to understand its specificity in the oral related lesions.

\section{Physiological role in oral cavity}

In the oral cavity, saliva is the prime area of acquiring numerous defense proteins. These proteins are like salivary immunoglobulins, and salivary chaperones which are involved in both innate and acquired immunity. The other important sources of salivary HSP70 / HSPAs are mucosal cells, gingival crevicular fluid, the oral mucosal transudate, and intraoral bleeding (i.e., bleeding periodontal pockets, wounds, ulcers). Saliva secretes Hsp70 as major molecular chaperones which are involved in a number of physiological and pathological events. Hsp70 can enter the bloodstream, and possess the ability to act at distant sites of the body as an ancestral danger signal triggered by cell injury, immune-inflammatory reactions, and physical or behavioral stress of the organism. Salivary Hsp70 may play a role in the prevention of bacterial infections and maintaining mucosal and periodontal health due to a continuous unspecific defensive alert $[82,83]$.

Hsp70/HspAs induces the release of proinflammatory cytokines from several immune cells such as monocytes, dendritic cells, macrophages, $\mathrm{T}$ lymphocytes and release of nitrous oxide from macrophages, activation of natural killer cells and activation of complement system via an alternative pathway. Another important function of Hsp70/HspAs is defense against bacteria, and an initiator of immune defense against tumor cells and virus-infected cells. This is achieved by its chaperoning ability where the un-complexed Hsp70/ HspA binds with other peptides, and as complex induces receptormediated uptake on to antigen-presenting cells and to further crosspresent this complex as an antigen to cytotoxic T cells and NK cells. The recent finding showed its opsonizing effect on bacteria, which in turn activate the killing activity of polymorphonuclear neutrophil granulocytes. These cytoprotective effects occurs either by aspecific binding of Hsp70/HspA on mucosal cell surfaces or specific adhesintype binding to sulfoglycolipid structures of mucosal cells or by direct surface receptor binding of Hsp70/HspAs [84-87].

Dental structures like odontoblasts (dentin forming cells) and pulpal cells (chiefly fibroblasts) showed to have high level of heat shock proteins. In vitro study by, Chen $\mathrm{Z}$, et al. revealed some expression of Hsps in the cultured dental pulp cells. Also, an animal study on rats indicated high level of HspAs in the odontoblast process following tooth dentin cavity preparation. HspAs are also thought to play an important role in the differentiation of newly formed odontoblast-like cells, which in turn play a major role in formation of reparative dentin [88].

\section{Inflammatory role}

Hsps play an important role in the harmful extension of inflammatory response of pulp arising from bacterial carious lesion in dentin and with several other restorative dental materials. Henderson B, et al. stated that the majority of immune stimulatory and modulatory functions of human and microbial Hsps come into action with a shifted balance toward immune activation and inflammation. In chronic periapical inflammation, the expression of Hsps appeared to be increased in inflammatory cells ie, lymphocytes and the endothelial 
cells present in the granulation tissues. Hsps can also stimulate bone resorption, probably by the initiation of pro-inflammatory cytokines, to activate osteoclastic activity $[89,90]$.

Literature reviewed data evidently specified that there are antibodies against human Hsps which may assist as autoantigens and initiate an autoimmune response that contributes to the initiation of gingivitis. The bone-resorptive action of Hsps also plays an important role in the progression of severe periodontal bone defects with pocket formation and the irreversible destruction of the periodontal bone. Vivas JR, et al. demonstrated increased Hsps level of mucosal cells in non-specific oral ulcerations and during gingival wound healing $[90,91]$.

Fábián TK, et al. showed marked overexpression of Hsps in cells located at the base of gastric ulcer and the level decreased with the progression of healing. It was suggested that both the extracellular and intracellular Hsps are coupled to work for defense mechanism in either of the following way: 1) Involuntary intracellular expression of Hsps increases the secretion of Hsps in extracellular space 2) The regulation of intracellular \& extracellular Hsps are mediated by alpha 1A-adrenoceptors 3) Extracellular Hsps are released by white blood cells present in wound fluid 4) In vivo transfer of Hsps increases the wound healing efficiency by the stimulation macrophages present in wound debris 5) Extracellular Hsps activate epidermal growth factor (EGF) receptors and related signaling pathways, which fastens the healing process $[83,92]$.

\section{Role in infection}

Microorganisms depend on host cell apparatus for productive infection. Like for many other processes, various organisms have been shown to evolve mechanisms to utilize or destabilize the host protective machinery to support the completion of their life cycle. Recent studies showed that some viruses encode for their own chaperone-like proteins to enhance their infectivity.

Lamb JR suggested that apart from the physiological roles, Hsps are implicated in the pathogenesis of various immune - mediated disorders such as infections (tuberculosis, chlamydia), autoimmune diseases (rheumatoid arthritis, multiple sclerosis), vascular thrombosis (atherosclerosis) and malignant disorders. Lehner, et al. suggested a molecular pathogenic mechanism of Hsps in Bechet's disease, wherein human Hsp responsive $\mathrm{T}$ cells are stimulated by microbial counterparts' triggered $\mathrm{T}$ cell activation and memory responses, thus influencing the chronicity and relapsing-remitting nature of this disease. Animal model study by Isogai E, et al. in 2000, presented that Hsp to oral mucosa increases Streptococcus sanguis colonisation, oral inflammatory cytokine expression (IL-2, I L - 6, IFN- $\gamma$ and TNF- $\alpha$ ) and mild iridocyclitis, indicating that stress might be critical to the breakdown of mucosal defences and anti-Hsp reactivity [93-95].

Several investigations have been established presenting a connection between Hsps of pathogenic microorganisms and their virulence potential, including Hsp90 and Hsp70 in the human fungal pathogen Candida albicans. Susek RE in 1990, unexpectedly demonstrated Hsp26 in non-pathogenic yeast 'Saccharomyces cerevisiae' which is neither required for growth at elevated temperatures, nor for thermotolerance, spore devolpment, or germination, although it showed accumulation in the cells during thermal and other stress conditions as a result of transcriptional derepression. Three sHsps have been identified in $C$. albicans i.e., Hsp10, Hsp12 and Hsp30/Hsp31 but the exact function remains unknown. Of these only $\mathrm{Hsp} 12$ has been characterized on a transcriptional level. Mayer FL, et al. demonstrated that sHsp is involved in Candida albicans adaptation to specific environmental stresses, homeostasis of intracellular stress protectants, immune evasion, as well as pathogenicity [96-99].

sHsps like Hsp21 contributes to adaptation to thermal and oxidative stress, but not to osmotic or cell wall stress and plays only a minor role in the unfolded protein response. Hsp21 acts in adaptation to nutrient limited conditions, which could be of importance during in vivo infections. It was postulated that Hsp21 may also play a role in morphogenesis of some of the fungal hyphae. The hsp21 mutant cells formed filamentous colonies under embedded conditions and on serum-containing agar; however, colonies appeared to be smaller than those of the wild type. The reduced colony size appeared to be mainly due to shorter radial filaments produced by the hsp 21 mutant in comparison to the wild type. Cowen and colleagues recently showed that heat-shock protein Hsp90 acts as physiological link between fungal morphogenesis and temperature $[99,100]$.

Increased expression of heat shock proteins is considered to be biomarkers for some viral infections. Viruses can regulate host chaperones at different levels, including transcription, translation, posttranslational modification, and cellular localization. Zhu, et al. expressed elevated expression of the heat shock protein GRP94 significantly correlating with the disease progression of hepatitis B virus (HBV) and suggested Hsps as a prognostic or diagnostic biomarker for HBV-induced diseases. Also, the upregulated expression of Hsp90 was reported in hepatocellular carcinomas or HBV-induced hepatic cancer [101].

Viruses are known to gain cellular entry by using viral un-coating mechanism or by conformational changes or by viral receptors. After internalization within host, viruses make their genome to be imported into the nucleus, for the replication. Cripe TP, et al. in their in vivo and in vitro study showed Hsp70 role in polyomavirus genome nuclear import through its association with viral capsid proteins. Replication of the viral genome with the expression of viral proteins, are well enhanced by host chaperons. Hsp90 has been demonstrated to be involved in the reverse transcription of HBV genome. Hu J and Anselmo D suggested that Hsp90 helps bridge the two separate reverse transcriptase domains of $\mathrm{HBV}$ together to enable the formation of a ribonucleoprotein complex with the HBV RNA. Few researchers showed that Hsp60 participate in the activation of HBV polymerase prior to its encapsidation into the core particle, which is required for initiating HBV replication in newly infected cells [102-105].

Chaperones assist the major function of folding and assembly of viral proteins and virions into functional conformations. Geller R, et al. recently suggested, Hsp90 to be involved in the process of viral capsid protein folding and assembly of various picornavirus, including poliovirus, rhinovirus, and coxsackie virus. A virion morphology study by Streblow DN revealed that the chaperone cyclophilin A 11 modulates HIV-1 infectivity through its interactions with viral gag structural proteins. Studies have also admitted that HIV-1 infection induces overexpression of Hsp70, which interacts with Hsp27 to protect cells from virus-induced G2 arrest and apoptosis. Tanaka, et al. reported that during $\mathrm{HBV}$ infection, $\mathrm{HBx}$ interaction with chaperone Hsp60 brings about their colocalization in the mitochondria, where Hsp60 promotes HBx-induced apoptosis. All these studies remarked chaperones role which can be utilized by viruses to participate in regulating cell apoptosis [106-108].

\section{Role in odontogenic cysts and tumors}

Hsps play an essential role at different stages of tooth development 
associated with cell proliferation, differentiation and death. It appears to be involved in the balance between differentiation and apoptosis, during the formation of calcified tissue. Hsps in odontogenic cyst and tumors are the most promising field of research. Kumamoto $\mathrm{H}$, et al revealed that sHsp 27 localized in human tooth germ is essential for cell growth. Also the expression of Hsp27 in ameloblastoma in his study was attributed towards tumor development. Fujita $\mathrm{M}$, et al emphasize the role of Hsp 27 in differentiation of tumor cells after observing the localization and differential expressions in histopathological subtypes of ameloblastoma $[109,110]$.

Andisheh-Tabdir A \& Fakharian M proposed the role of Hsp 70 in the aggressive behavior of ameloblastoma and the high recurrence in odontogenic keratocyst. The high expression of Hsp 70 have a possible role in pathogenesis of odontogenic cyst and tumors. Lorenzo LM, et al. analyzed immunohistochemical positive staining of Hsp 27 in proliferating epithelial cell rests and radicular cysts with or without inflammatory cells. Most of the cyst types presented cytoplasmic immunolabelling of epithelial cells, which might interplay in the pathogenesis of periapical orodental lesions including the induction of epithelial cell rests migration and the increased resistance both to necrosis and apoptosis [111,112].

Role of Hsps in the cell differentiation was studied by Fujita M, et al. in 2013. Hsp 27 was detected in odontogenic epithelium of tooth germ, dental lamina, enamel organ, slightly in dental papilla and mesenchymal cells of dental follicle and in benign and malignant odontogenic tumors. In the study, Hsp27 was strongly expressed by tumor cells of ameloblastoma but not by fibroblasts and vascular endothelial cells present in the stroma. High positive reaction rate in stellate-shaped cells and those cells undergoing squamous metaplasia in the parenchyma of follicular type was evident. It is considered that Hsp27 were involved in the transformation of tumor cells to squamous metaplasia. Tumor cells in ameloblastoma have short life span with cells mostly having squamous characteristics, in primary cultures collected from the lesion. He believed that injury to the tumor cells occurred during tissue collection resulting in activation of Hsps. Also, suggested that Hsps are involved in the differentiation of the columnar and cuboidal tumor cells to squamous cell in tissue cultures of ameloblastoma. This was in supported by Muraki, et al. [113,114].

\section{Role in pre-malignancy and malignancy}

Hsps are released and are present in the extracellular environment under physiological/pathological conditions. They can elicit cytokine production and adhesion molecule expression in various cell types, and can deliver maturation signals and peptides to antigen presenting cells through receptor-mediated interactions. The overexpression of Hsp in tumor cells, help in the exposure of accumulated hidden mutations in tumors and further progression to more aggressive types of malignant/ metastatic cells $[115,116]$.

HSPs with the increased expression are a common feature of both solid tumors and haematological malignancies. At proteomic level, increased Hsps activities might allow tumor cells to survive with the excessive signalling associated with malignant transformation, and thus seepage the apoptotic death. Hsp90, Hsp70, and Hsp27 act in inhibiting apoptosis by binding to procaspases. Other role suggested includes Hsp27 in enhancing the tumorigenicity of colon carcinoma cells, HSP70 highly expressed in human breast tumors \& HSP90 in prostate carcinomas. Jameel A, et al and Yano M studied that in breast cancer overexpression of HSP70 and HSP90 is suggestive poor prognosis. Kimura E, et al. \& Nanbu K, et al. showed overexpression of HSP70 and HSP27 might contribute to drug resistance and poor response to combination-chemotherapy regimens [117-122].

HSP27 expression is known to be associated with increased tumorogenicity, growth rate or invasiveness of some carcinomas. Zhu, et al. observed overexpression of HSP27 in head and neck squamous cell carcinoma \& confirmed that reduced HSP27 expression is associated with poor differentiation whereas the higher expression shows better overall survival. Fan, et al. observed the high expression of HSP60 in oral dysplastic lesion such as leukoplakia and oral squamous cell carcinoma. HSP60 expressions are thought to be associated with histopathological characteristics and clinical features. HSP70 overexpression was observed in premalignant oral lesions which were correlated with a high risk of transition to malignancy. High Hsp70 also observed in other oral dysplastic lesions like oral verrucous carcinoma, oral verrucous hyperplasia, oral lichen planus $[123,124]$.

Kawanishi, et al. investigated the expression of Hsp 27 and Hsp105 in 102 specimens of esophageal SCCs and stated these two as valuable prognostic markers. Also, Hsp27 is strongly associated with clinicopathologic characteristics and its expression is in reverse relationship with clinical stage. Nakajima, et al. found no relationship between the rate of Hsp27 expression and histological grading in esophageal SCCs which lead Mohtasham N, et al. to conclude that tumors with identical pathology may express different biologic behaviors when emerge in different tissues [125-127].

\section{Therapeutic approach of chaperones}

Various molecular chaperones like (Hsp 70, Hsp 90, Hsp 100, Hsp 40), chemical chaperones (glycerol etc.) and pharmacological (amyloidoses, capsaicin, cycloporin, Vinblatin, verapamil etc) chaperones, have been studied experimentally and reported to reverse the mutational effect of the protein conformation and suppress the phenotype [128].

Chemical chaperones are low molecular mass compounds known to stabilize protein conformation against thermal and chemical denaturation. They are effective in inhibiting the formation of misfolded structure and subsequent amyloid formation. Chemical chaperones have shown to reverse the intracellular retention of several different misfolded proteins such as CFTR, $\alpha$-antitrypsin, aquaporin-2, vasopressin V2 receptor, $\alpha$-galactosidase A, p53 and P-glycoprotein. Pharmacological chaperones have proved very effective in rescuing a few receptor proteins from proteasomal degradation. Pharmacological ligands act by binding to specific conformations of receptor proteins and stabilizing them. Model for the mode of action of pharmacological chaperones was proposed by Morello, et al. [128-131].

The cytotoxic and cytostatic anticancer activities have been reported for Hsp90 inhibitors in cell-culture models and animal tumor models. Interruption of anti-apoptotic signaling in tumor cells occurs following exposure to Hsp90 inhibitors and can enhance the pro-apoptotic effects of cytotoxic agents. Whether such disruption is required and/ or adequate for the anticancer activity of Hsp90 inhibitors, conversely, remains less distinct. There exists the possibility that by inhibiting Hsp90 buffering activity at certain stages of malignant progression might reveal mutations that enhance the survival and malignant progression of some cells within the population. Although modulation of Hsp90 function provides a mechanistically attractive target for the treatment of cancer. In the recent reports that up-regulation of the Hsp70 can somehow subdue the neurotoxicity of certain amyloidogenic proteins, thereby aiming toward chaperones, as favorable targets towards 
treatment of protein misfolding or aggregation or conformational diseases [128,132-135].

In cancer therapy, there always remain two important challenges. 1) Retaining the target specificity by improving the pharmacological properties of current agents. 2) Defining the suitable way to administer Hsp inhibitors in treating cancers. The known biological activities and early clinical results indicate that Hsps will be more useful as modulators of response towards cancer and to other therapeutic interventions. These might be useful modulators of the tumorigenesis, which is a main obstacle to curative therapy.

\section{Conclusion}

With the advancements in the genomic and proteomics in advanced biomedical sciences, many possibilities have evolved with the subsequent discoveries in the clinical cancer research including identification of molecular and chemical biomarkers, classification of diseases, metastasis, treatment plan and prognosis. Understanding in detail the complex functions of the chaperones might be useful in near future, for exploring the mechanisms behind the diseases caused by either protein misfolding or aggregation.

\section{Acknowledgement}

We would like to acknowledge the Management, Dean and Vice Dean of Buraydah Private Dental College for allowing us to carry out our work successfully.

\section{References}

1. Ranford J C, Anthony RMC, Henderson B (2000) Chaperonins are cell-signalling proteins: the unfolding biology of molecular chaperones. Exp Rev Mol Med 1: 1-15.

2. Laskey RA, Honda BM, Mills AD, Finch JT (1978) Nucleosomes are assembled by an acidic protein which binds histones and transfers them to DNA. Nature 275: 416-420. [Crossref]

3. Hartl FU (1996) Molecular chaperones in cellular protein folding. Nature 381: 5719

4. Hartl, FU, Hayer-Hartl M (2009) Converging concepts of protein folding in vitro and in vivo." Nat Struct Mol Biol 16: 574-81. [Crossref]

5. Dobson CM, Fersht AR (1995) Protein Folding, 1995 Cambridge University Press, UK.

6. Gething MJ (1997) Guidebook to Molecular Chaperones and Protein-folding Catalysts. Oxford University Press, UK.

7. Bukau B, Horwich AL (1998) The Hsp70 and Hsp60 chaperone machines. Cell 92: 351-366. [Crossref]

8. Hemmingsen SM, Woolford C, Van Der VSM, Tilly K, Dennis DT, et al (1988) Homologous plant and bacterial proteins chaperone oligomeric protein assembly. Nature 333: 330-334. [Crossref]

9. Vos M J, Hageman J, Carra S, Kampinga HH (2008) Structural and functional diversities between members of the human HSPB, HSPH, HSPA, and DNAJ chaperone families. Biochemistry 47: 7001-7011. [Crossref]

10. Dobson C, Karplus M (1999) The fundamentals of protein folding: bringing together theory and experiment. Curr Opin Struct Biol 9: 92-101. [Crossref]

11. Radford SE (2000) Protein folding: progress made and promises ahead. Trends Biochem Sci 25: 611-8. [Crossref]

12. Hart FU, Hayer-Hartl M (2002) Molecular Chaperones in the Cytosol: from Nascent Chain to Folded Protein. Science 295: 1852-1858. [Crossref]

13. Langer T, Lu C, Echols H, Flanagan J, Hayer MK, et al. (1992) Successive action of DnaK, DnaJ and GroEL along the pathway of chaperone-mediated protein folding. Nature 356: 683-689. [Crossref]

14. Frydman J, Nimmesgern E, Ohtsuka K, Hartl FU (1994) Folding of nascent polypeptide chains in a high molecular mass assembly with molecular chaperones. Nature 370: 111117. [Crossref]
15. Siegers K, Waldmann T, Leroux MR, Grein K, Shevchenko A, et al. (1999) Compartmentation of protein folding in vivo: sequestration of non-native polypeptide by the chaperonin-GimC system. EMBO J 18: 75-84. [Crossref]

16. Deuerling E, Schulze-Specking A, Tomoyasu T, Mogk A, Bukau B (1999) Trigger factor and DnaK cooperate in folding of newly synthesized proteins. Nature 400: 693 696. [Crossref]

17. Teter SA, Houry WA, Ang D, Tradler T, Rockabrand D, et al. (1999) Polypeptide Flux Through Bacterial Hsp70: DnaK Cooperates with Trigger Factor in Chaperoning Nascent Chains. Cell 97: 755-765. [Crossref]

18. Thulasiraman V, Yang CF, Frydman J (1999) In vivo newly translated polypeptides are sequestered in a protected folding environment. EMBO J 18: 85-95. [Crossref]

19. Cheetham ME, Caplan AJ (1998) Structure function and evolution of DnaJ conservation and adaptation of chaperone function. Cell Stress Chaperones 3: 28-36. [Crossref]

20. Fan CY, Lee S, Cyr DM (2003) Mechanisms for regulation of Hsp70 function by Hsp40. Cell Stress Chaperones 8: 309-316. [Crossref]

21. Venter JC, Adams MD, Myers EW, Peter WL, Richard JM, et al. (2001) The sequence of the human genome. Science 291: 1304-1351. [Crossref]

22. Liberek K, Marszalek J, Ang D, Georgopoulos C, Zylicz M (1991) Escherichia coli DnaJ and GrpE heat shock proteins jointly stimulate ATPase activity of DnaK. Proc Natl Acad Sci U S A 88: 2874-2878. [Crossref]

23. Wickner S, Hoskins J, McKenney K (1991) Monomerization of RepA dimers by heat shock proteins activates binding to DNA replication origin. Proc Natl Acad Sci US A 88: 7903-7907. [Crossref]

24. Langer T, Lu C, Echols H, Flanagan J, Hayer MK, et al. (1992) Successive action of DnaK DnaJ and GroEL along the pathway of chaperone-mediated protein folding. Nature 356: 683-689.

25. Palleros DR, Reid KL, Shi L, Welch WJ, Fink AL (1993) ATP-induced protein-Hsp70 complex dissociation requires K1 but not ATP hydrolysis. Nature 365: 664-666.

26. Cyr DM, Langer T, Douglas MG (1994) DnaJ-like proteins: molecular chaperones and specific regulators of Hsp70. Trends Biochem Sci 19: 176-181. [Crossref]

27. Brodsky JL, Schekman R (1993) A Sec63p-BiP complex from yeast is required for protein translocation in a reconstituted proteoliposome. J Cell Biol 123: 1355-1363. [Crossref]

28. Shen Y, Meunier L, Hendershot LM (2002) Identification and characterization of a novel endoplasmic reticulum (ER) DnaJ homologue which stimulates ATPase activity of BiP in vitro and is induced by ER stress. J Biol Chem 277: 15947-15956. [Crossref]

29. Yochem J, Uchida H, Sunshine M, Saito H, Georgopoulos CP, et al. (1978) Genetic analysis of two genes dnaJ and dnaK necessary for Escherichia coli and bacteriophage lambda DNA replication. Mol Gen Genet 164: 9-14. [Crossref]

30. Landry SJ (2003) Structure and energetics of an allele-specificgenetic interaction between dnaJ and dnaK: correlation of nuclear magnetic resonance chemical shift perturbations in the J-domain of Hsp40/DnaJ with binding affinity for the ATPase domain of Hsp70/DnaK. Biochemistry 42: 4926-4936. [Crossref]

31. Bukau B, Horwich AL (1998) The Hsp70 and Hsp60 chaperone machines. Cell 92 351-366. [Crossref]

32. Buchberger A, Valencia A, McMacken R, Sander C, Bukau B. The chaperone function of DnaK requires the coupling of ATPase activity with substrate binding through residue E171. EMBO J 13: 1687-1695. [Crossref]

33. Montgomery DL, Morimoto RI, Gierasch LM (1999) Mutations in the substrate binding domain of the Escherichia coli $70 \mathrm{kDa}$ molecular chaperone DnaK which alter substrate affinity or interdomain coupling. J Mol Biol 286: 915-932. [Crossref]

34. Bukau B, Horwich AL (1998) The Hsp70 and Hsp60 chaperone machines. Cell 92 351-366. [Crossref]

35. Ranson NA, White HE, Saibil HR (1998) Chaperonins. Biochem J 333: 233-242. [Crossref]

36. Feltham JL, Gierasch LM (2000) GroEL-substrate interactions: molding the fold, or folding the mold? Cell 100: 193-196. [Crossref]

37. Ewalt KL,Hendrick JP, Houry WA, Hartl FU (1997) In vivo observation of polypeptide flux through the bacterial chaperonin system. Cell 90: 491-500. [Crossref]

38. Fenton WA, Kashi Y, Furtak K, Norwich A (1994) Residues in chaperonin GroEL required for polypeptide binding and release. Nature 371, 614-619. [Crossref] 
39. Braig K, Otwinowski Z, Hegde R, Boisvert DC, Joachimiak A, et al. (1994) The crystal structure of the bacterial chaperonin GroEL at 2.8 A. Nature 371, 578-586. [Crossref]

40. Chandrasekhar GN, Tillys K, Woolford C, Hendrixll R, Georgopoulos C (1986) Purification and properties of the groES morphogenetic protein of Escherichia coli. $J$ Biol Chem 261: 12414-12419.

41. Saibil H (1996) The lid that shapes the pot: structure and function of the chaperonin GroES. Structure 4: 1-4. [Crossref]1990)

42. Alder GM, Austen BM, Bashford CL, Mehlert A, Pasternak CA (1990) Heat shock proteins induce pores in membranes. Biosci Rep 10: 509-518. [Crossref]

43. Kirby AC, Meghji S, Nair SP, White P, Reddi K, et al. (1995) The potent bone resorbing mediator of Actinobacillus actinomycetemcomitans is homologous to the molecular chaperone GroEL. J Clin Invest 96: 1185-1194. [Crossref]

44. Nair SP, Meghji S, Reddi K, Poole S, Miller AD, et al. (1999) Molecular chaperones stimulate bone resorption. Calcif Tissue Int 64: 214-218. [Crossref]

45. Gribaldo S, Lumia V, Creti R, Conway de Macario E, Sanangelantoni A, et al. (1999) "Discontinuous occurrence of the hsp70 (dnaK) gene among Archaea and sequence features of HSP70 suggest a novel outlook on phylogenies inferred from this protein. $J$ Bacteriol 81: 434-43. [Crossref]

46. Ungermann C, Neupert W, Cyr DM (1994) The role of Hsp70 in conferring unidirectionality on protein translocation into mitochondria. Science 266: 1250-1253. [Crossref]

47. Dey B, Caplan AJ, Boschelli (1996) The Ydj1 molecular chaperone facilitates formation of active p60v-src in yeast. Mol Biol Cell 7: 91-100. [Crossref]

48. Liu JS, Kuo SR, Makhov AM, Cyr DM, Griffith JD, et al. (1998) Human Hsp70 and Hsp40 chaperone proteins facilitate human papillomavirus-11 E1 protein binding to the origin and stimulate cell-free DNA replication. J Biol Chem 273: 30704- 30712. [Crossref]

49. Meacham GC, Lu Z, King S, Sorscher E, Tousson A, et al. (1999b) The Hdj-2/Hsc70 chaperone pair facilitates early steps in CFTR biogenesis. EMBO $J$ 18: 1492-1505. [Crossref]

50. Gall WE, Higginbotham MA, Chen C, Ingram MF, CyrDM, et al. (2000) The auxilinlike phosphoprotein Swa2p is required for clathrin function in yeast. Curr Biol 10: 1349-1358. [Crossref]

51. Horton LE, James P, Craig EA, Hensold JO (2001) The yeast hsp70 homologue Ssa is required for translation and interacts with $\mathrm{Sis} 1$ and $\mathrm{Pab} 1$ on translating ribosomes. $J$ Biol Chem 276: 14426- 14433. [Crossref]

52. Daugaard M, Rohde M, Jaattela M (2007) The heat shock protein 70 family: Highly homologous proteins with overlapping and distinct functions. FEBS Lett 581: 3702-10. [Crossref]

53. Hageman J, Kampinga HH (2009) Computational analysis of the human HSPH/HSPA/ DNAJ family and cloning of a human HSPH/HSPA/DNAJ expression library. Cell Stress Chaperones 14: 1-21. [Crossref]

54. Brocchieri L, Conway de Macario E, Macario AJ (2008) Hsp70 genes in the human genome: Conservation and differentiation patterns predict a wide array of overlapping and specialized functions. BMC Evol Biol 8: 19. [Crossref]

55. Albanese V, Yam AY, Baughman J, Parnot C, Frydman J (2006) Systems analyses reveal two chaperone networks with distinct functions in eukaryotic cells. Cell 124: 75-88. [Crossref]

56. Gabai VL, Meriin AB, Mosser DD, Caron AW, Rits S, et al. (1997) Role of the human heat shock protein hsp70 in protection against stress-induced apoptosis. $J$ Biol Chem 272: 18033-18037. [Crossref]

57. Beere HM, Green DR (2001) Stress management-heat shock protein-70 and the regulation of apoptosis. Trends Cell Biol 11: 6-10. [Crossref]

58. Creagh EM, Carmody RJ, Cotter TG (2000) Heat shock protein 70 inhibits caspasedependent and -independent apoptosis in Jurkat T cells. Exp Cell Res 257: 58-66.

59. Ravagnan L, Gurbuxani S, Susin SA, Maisse C, Daugas E, et al. (2001) Heat shock protein 70 antagonizes apoptosis-inducing factor. Nat Cell Biol 3: 839-843. [Crossref]

60. Li CY, Lee JS, Ko YG, Kim JI, Seo JS (2000) Heat shock protein 70 inhibits apoptosis downstream of cytochrome c release and upstream of caspase-3 activation. J Biol Chem 275: 25665-25671. [Crossref]

61. Wegele H, Muller L, Buchner J (2004) Hsp70 and Hsp90--a relay team for protein folding. Rev Physiol Biochem Pharmacol 151: 1-44. [Crossref]
62. Zhao R, Davey M, Hsu YC, Kaplanek P, Tong A, et al. (2005) Navigating the chaperone network: an integrative map of physical and genetic interactions mediated by the hsp 90 chaperone. Cell 120: 715-727. [Crossref]

63. Pandey P, Saleh A, Nakazawa A, Kumar S, Srinivasula SM, et al. (2000b) Negative regulation of cytochrome c-mediated oligomerization of Apaf-1 and activation of procaspase-9 by heat shock protein 90. EMBO J 19: 4310-4322. [Crossref]

64. Voos W, Rottgers K (2002) Molecular chaperones as essential mediators of mitochondrial biogenesis. Biochimica et Biophysica Acta 1592: 51-62. [Crossref]

65. Koyasu S, Nishidat E, Kadowakif T, Matsuzaki F, Iida K, et al. (1986) Two mammalian heat shock proteins, HSP90 and HSP100, are actin-binding proteins. Proc Natl Acad Sci U S A 83:8054-8058. [Crossref]

66. Schmitt M, Neupert W, Langer T (1996) The molecular chaperone Hsp78 confers compartment-specific thermotolerance to mitochondria. J Cell Biol 134: 1375-1386. [Crossref]

67. Nakamoto H, Vigh L (2007) The small heat shock proteins and their clients. Cell Mol Life Sci 64: 294-306. [Crossref]

68. Gusev NB, Bogatcheva NV, Marston SB (2002) Structure and properties of small heat shock proteins $(\mathrm{sHsp})$ and their interaction with cytoskeleton proteins. Biochemistry 67: 613-623. [Crossref]

69. Kappe G, Boelens WC, de Jong WW (2010) Why proteins without an alpha-crystallin domain should not be included in the human small heat shock protein family HSPB. Cell Stress Chaperones 15: 457-461. [Crossref]

70. Carver JA (1999) Probing the structure and interactions of crystallin proteins by NMR spectroscopy. Prog Retin Eye Res 18: 431-462. [Crossref]

71. Kriehuber T, Rattei T, Weinmaier T, Bepperling A, Haslbeck M, et al. (2010) Independent evolution of the core domain and its flanking sequences in small heat shock proteins. FASEB J 24: 3633-3642. [Crossref]

72. MacCoss MJ, McDonald WH, Saraf A, Sadygov R, Clark JM, et al. (2002) Shotgun identification of protein modifications from protein complexes and lens tissue. Proc Natl Acad Sci USA 99: 7900-7905. [Crossref]

73. Benjamin IJ, McMillan DR (1998) Stress (heat shock) proteins: molecular chaperones in cardiovascular biology and disease. Circ Res 83: 117-132. [Crossref]

74. Sugiyama Y, Suzuki A, Kishikawa M, Akutsu R, Hirose T, et al. (2000) Muscle develops a specific form of small heat shock protein complex composed of MKBP/ HSPB2 and HSPB3 during myogenic differentiation. J Biol Chem 275: 1095- 1104 [Crossref]

75. Mosser DD, Morimoto RI (2004) Molecular chaperones and the stress of oncogenesis. Oncogene 23: 2907-2918. [Crossref]

76. Kamradt MC, Meiling L, Werner ME, Kwan T, Chen F, et al. (2001) The small heat shock protein $\alpha \mathrm{B}$-crystallin is a novel inhibitor of TRAIL-induced apoptosis that suppresses the activation of Caspase-3 (2001). J Biol Chem 276: 16059-16063.

77. Benndorf R, Sun X, Gilmont RR, Biederman KJ, Molloy MP, et al. (2001) HSP22, a new member of the small heat shock protein superfamily, interacts with mimic of phosphorylated HSP27 ((3D) HSP27). J Biol Chem 276: 26753-26761. [Crossref]

78. Loktionova SA, Ilyinskaya OP, Gabai VL, Kabakov AE (1996) Distinct effects of heat shock and ATP depletion on distribution and isoform patterns of human Hsp27 in endothelial cells. FEBS Lett 392: 100-104. [Crossref]

79. Wang P, Bitar K, Rho (1998) A regulates sustained smooth muscle contraction through cytoskeletal reorganization of HSP27. Am J Physiol 275: G1454 - G1462. [Crossref]

80. Ibitayo AI, Sladick J, Tuteja S, Louis JO, Yamada H, et al. (1999) HSP27 in signal transduction and association with contractile proteins in smooth muscle cells. Am J Physiol 277: G445 - G454. [Crossref]

81. Lavoie JN, Lambert H, Hickey E, Weber LA, Landry J (1995) Induction of Chinese hamster HSP27 gene expression in mouse cells confer resistance to heat shock. HSP27 stabilization of the microfilament organization. Mol Cell Biol 15: 505-516. [Crossref]

82. Fabian TK, Hermann P, Beck A, Fejerdy P, Fabian G (2012) Salivary Defense Proteins: Their Network and Role in Innate and Acquired Oral Immunity. Int J Mol Sci 13: 42954320. [Crossref]

83. Fabian TK, Fejerdy P, Nguyen MT, Soti C, Csermely P (2007) Potential immunologica functions of salivary Hsp70 in mucosal and periodontal defense mechanisms. Arch Immunol Ther Exp 55: 1-8. [Crossref]

84. Campisi J, Leem TH, Fleshner M (2003) Stress-induced extracellular Hsp72 is a 
functionally significant danger signal to the immune system. Cell Stress Chaperones 8: 272-286. [Crossref]

85. Srivastava PK (2002) Heat shock proteins in innate and adaptive immunity. Nat Rev Immunol 2: 185-194. [Crossref]

86. Johnson AD, Tytell M (1993) Exogenous Hsp70 becomes cell associated, but not internalized by stressed arterial smooth muscle cells. In Vitro Cell Dev Biol Anim 29: 807-812. [Crossref]

87. Boulanger J, Faulds D, Eddy EM, Lingwood CA (1995) Members of the $70 \mathrm{kDa}$ heat shock protein family specifically recognize sulfoglycolipids: Role in gameterecognition and mycoplasma-related infertility. J Cell Physiol 165: 7-17. [Crossref]

88. Chen Z, Fan M, Bian Z, Zhang Q, Zhu Q, et al. (2000) Immunolocalization of heat shock protein 70 during reparative dentinogenesis. Chin J Dent Res 3: 50-5. [Crossref]

89. Henderson B, Allan E, Coates ARM (2006) Stress wars: the direct role of host and bacterial molecular chaperones in bacterial infection. Infect Immunity 74: 3693-3706. [Crossref]

90. Nair SP, Meghji S, Reddi K, Poole S, Miller AD, et al. (1999) Molecular chaperones stimulate bone resorption. Calcif Tissue Int 64: 214-218.

91. Ikai H, Tamura T, Watanabe T, Itou M, Sugaya A, et al. (2008) Lowintensity pulsed ultrasound accelerates periodontal wound healing after flap surgery. J Periodontal Res 43: 212-216. [Crossref]

92. Kovalchin JT, Wang R, Wagh MS, Azoulay J, Sanders M, et al. (2006) In vivo delivery of heat shock protein 70 accelerates wound healing by up-regulating macrophagemediated phagocytosis. Wound Repair Regen 14: 129-137. [Crossref]

93. Lamb JR, Young DB (1990) T cell recognition of stress proteins: a link between infectious and autoimmune diseases. Mol Biol Med 7: 311-321. [Crossref]

94. Lehner T (1997) The role of heat shock protein, microbial and auto-immune agents in the aetiology of Behçet's disease. Intern Rev Immunol 14: 21-32. [Crossref]

95. Isogaie E, Isogaih H, Yokota K, Oguma K, Kimura K, et al. (2000) Experimental mode for Behçet's disease in gnotobiotic mice infected with Streptococcus sanguis. In: Bang D, Lee ES, Lee S (Eds): Behçet's Disease, Seoul, Design Mecca Publishing Co pp: 133-142.

96. Cowen LE, Singh SD, Kohler JR, Collins C, Zaas AK, et al. (2009) Harnessing Hsp90 function as a powerful, broadly effective therapeutic strategy for fungal infectious disease. Proc Natl Acad Sci U S A 106: 2818-2823. [Crossref]

97. Sun JN, Solis NV, Phan QT, Bajwa JS, Kashleva H, et al. (2010) Host cell invasion and virulence mediated by Candida albicans Ssa1. PLoS Pathog 6: e1001-1181. [Crossref]

98. Susek RE, Lindquist S (1990) Transcriptional derepression of the Saccharomyces cerevisiae HSP26 gene during heat shock. Mol Cell Biol 10: 6362-6373. [Crossref]

99. Mayer FL, Wilson D, Jacobsen ID, Miramon P, Slesiona S, et al. (2012) Small but Crucial: The novel small heat shock protein Hsp21 mediates stress adaptation and virulence in Candida albicans. PLoS ONE 7: e3858. [Crossref]

100. Shapiro RS, Uppuluri P, Zaas AK, Collins C, Senn H, et al. (2009) Hsp90 orchestrates temperature-dependent Candida albicans morphogenesis via Ras1-PKA signaling. Curr Biol 19: 621-629. [Crossref]

101. Zhu XD, Li CL, Lang ZW, Gao GF, Tien P (2004) Significant correlation between expression level of HSP gp96 and progression of hepatitis B virus induced diseases. World J Gastroenterol 10: 1141-1145. [Crossref]

102. Cripe TP, Delos SE, Estes PA, Garcea RL (1995) In vivo and in vitro association of hsc70 with polyomavirus capsid proteins. J Virol 69: 7807-7813. [Crossref]

103. Hu J, Anselmo D (2000) In vitro reconstitution of a functional duck hepatitis B virus reverse transcriptase: posttranslational activation by Hsp90. J Virol 74: 11447-11455. [Crossref]

104. Park SG, Jung G (2001) Human hepatitis B virus polymerase interacts with the molecular chaperonin Hsp60. J Virol 75: 6962-6968. [Crossref]

105. Stahl M, Retzlaff M, Nassal M, Beck J (2007) Chaperone activation of the hepadnaviral reverse transcriptase for template RNA binding is established by the Hsp70 and stimulated by the Hsp90 system. Nucleic Acids Res 35: 6124-6136. [Crossref]

106. Geller R, Vignuzzi M, Andino R, Frydman J (2007) Evolutionary constraints on chaperone-mediated folding provide an antiviral approach refractory to development of drug resistance. Genes Dev 1: 195-205. [Crossref]

107. Streblow DN, Kitabwalla M, Malkovsky M, Pauza CD (1998) Cyclophilin a modulates processing of human immunodeficiency virus type $1 \mathrm{p} 55 \mathrm{Gag}$ : mechanism for antiviral effects of cyclosporin A. Virology 245: 197-202. [Crossref]

108. Tanaka Y, Kanai F, Kawakami T, Tateishi K, Ijichi H, et al. (2004) Interaction of the hepatitis B virus X protein ( $\mathrm{HBx}$ ) with heat shock protein 60 enhances $\mathrm{HBx}$-mediated apoptosis. Biochem Biophys Res Commun 318: 461-469. [Crossref]

109. Kumamoto H, Suzuki T, Ooya K (2002) Immunohistochemical analysis of inducible nitric oxide synthase (iNOS) and heat shock proteins (HSPs) in ameloblastomas. $J$ Oral Pathol Med 31: 605-11. [Crossref]

110. Fujita M, Nakano K, Maeda H, Yoshida W, Torii R, et al. (2011) Immunohistochemical observation of HSP27 in ameloblastomas. J Hard Tissue Biol 20: 289-294.

111. Andisheh-Tadbir A, Fakharian M (2015) HSP70 expression in dentigerous cyst, odontogenic keratocyst, and ameloblastoma. Oral Maxillofac Surg 19: 287. [Crossref]

112. Lorenzo LM, Francesco CAS, Rosalia L (2011) Expression of heat shock protein 27 in odontogenic cysts. European Journal of Inflammation 9: 33-42.

113. Fujita M, Nakano K, Funato A, Sugita Y, Kubo K, et al. (2013) Heat Shock Protein27 expression and cell differentiation in ameloblastomas. Int J Med Sci 10: 1271-1277. [Crossref]

114. Muraki E, Nakano K, Maeda H, Takayama M, Jinno M, et al. (2011) Immunohistochemical localization of Notch signaling molecules in ameloblastomas. Eur J Med Res 16: 253-257. [Crossref]

115. Charu Kapoor, Sharad Vaidya (2013) Heat shock protein (HSP) and cancer: An overview. Am J Med Dent Sci 1: 31-34.

116. Caporale LH (1999) Chance favors the prepared genome. Ann NY Acad Sci 870:1- 21 [Crossref]

117. Garrido C, Fromentin A, Bonnotte B, Favre N, Moutet M, et al. (1998) Heat shock protein 27 enhances the tumorigenicity of immunogenic rat colon carcinoma cells. Cancer Res 58: 5495- 5499. [Crossref]

118. Nylandsted J, Rohde M, Brand K, Bastholm L, Elling F, et al. (2000) Selective depletion of heat shock protein 70 (Hsp70) activates a tumor-specific death program that is independent of caspases and bypasses Bcl-2. Proc Natl Acad Sci USA 97: 78717876. [Crossref]

119. Jameel A, Skilton RA, Campbell TA, Chander SK, Coombes RC, et al. (1992) Clinical and biological significance of Hsp90a in human breast cancer. Int J Cancer 50: 409 415 .

120. Yano M, Naito Z, Tanaka S, Asano G (1996) Expression and roles of heat shock proteins in human breast cancer. Jpn J Cancer Res 87: 908-915. [Crossref]

121. Kimura E, Enns RE, Alcaraz JE, Arboleda J, Slamon DJ, et al. (1993) Correlation of the survival of ovarian cancer patients with mRNA expression of the $60 \mathrm{kDa}$ heat shock protein Hsp60. J Clin Oncol 11: 891-898.

122. Nanbu K, Konishi I, Mandai M, Kuroda H, Hamid AA, et al. (1998) Prognostic significance of heat shock proteins HSP70 and HSP90 in endometrial carcinomas. Cancer Detection \& Prevention 22: 549-555. [Crossref]

123. Tekkeșin MS, Mutlu S, Aksakall N, Olgaç Vakur (2011) Expression of heat shock proteins 27, 60 and 70 in oral carcinogenesis: An immunohistochemical study. Turk Onkoloji Dergisi 26: 115-120.

124. Mary NJ, Prashanth K, Jaysheel AS (2016) Estimation of Serum Levels of Heat Shock Proteins (HSP) - 70 in patients with oral dysplastic lesions of leukoplakia. J Cont Med A Dent 4: 70-73.

125. Kawanishi K, Shiozaki H, Doki Y, Sakita I, Inoue M, et al. (1999) Prognostic significance of heat shock proteins 27 and 70 in patients with squamous cell carcinoma of the esophagus. Cancer 85: 1649-1657. [Crossref]

126. Nakajima M, Kuwano H, Miyazaki T, Masuda N, Kato H (2002) Significant correlation between expression of heat shock proteins 27,70 and lymphocyte infiltration in esophageal squamous cell carcinoma. Cancer Lett 178: 99-106. [Crossref]

127. Mohtasham N, Babakoohi S, Montaser-Kouhsari L, Memar B, Salehinejad J, et al (2011) The expression of heat shock proteins 27 and 105 in squamous cell carcinoma of the tongue and relationship with clinicopathological index. Med Oral Patol Oral Cir Bucal 16: e730-735. [Crossref]

128. Whitesell L, Lindquist SL (2005) HSP90 and the chaperoning of cancer. Nature Reviews Cancer 5: 761-772. [Crossref]

129. Enmon R, Yang WH, Ballangrud AM, Solit DB, Heller G, et al. (2003) Combination treatment with 17-Nallylamino-17-demethoxy geldanamycin and acute irradiation produces supra-additive growth suppression in human prostate carcinoma spheroids. Cancer Res 63: 8393-8399. 
130. Queitsch C, Sangster TA, Lindquist S (2002) Hsp90 as a capacitor of phenotypic variation. Nature 417: 618-624.

131. Nomura M, Nomura N, Newcomb EW, Lukyanov Y, Tamasdan C, et al. (2004) Geldanamycin induces mitotic catastrophe and subsequent apoptosis in human glioma cells. J Cell Physiol 201: 374-384. [Crossref]

132. Holt SE, Aisner DL, Baur J, Tesmer VM, Dy M, et al. (1999) Functional requirement of p23 and Hsp90 in telomerase complexes. Genes Dev 13: 817-824. [Crossref]
133. Basso AD, Solit DB, Munster PN, Rosen N (2002) Ansamycin antibiotics inhibit Akt activation and cyclin D expression in breast cancer cells that overexpress HER2. Oncogene 21: 1159-1166. [Crossref]

134. Kazemi-Esfarjani P, Benzer S (2000) Genetic suppression of polyglutamine toxicity in Drosophila. Science 287: 1837 - 1840. [Crossref]

135. Cummings CJ, Sun Y, Opal P, Antalffy B, Mestril R, et al. (2001) Over-expression of inducible HSP70 chaperone suppresses neuropathology and improves motor function in SCA1 mice. Hum Mol Genet 10: 1511-1518. [Crossref]

Copyright: (C2017 Kashyap B. This is an open-access article distributed under the terms of the Creative Commons Attribution License, which permits unrestricted use, distribution, and reproduction in any medium, provided the original author and source are credited. 